\title{
Marianne Braig \\ Los derechos humanos como autorización para hablar. Metatexto universal y experiencias particulares
}

\begin{abstract}
Fue junto con Manuela cuando escuché por primera vez a los catequistas decir que no está bien que sólo esté mandando el hombre y que no está bien que sólo esté dando patadas a la mujer. [...] Decían que también tenemos derechos las mujeres de que nos toman en cuenta, de que nos quieren. Debemos ser iguales, juntos tenemos que pensar y decidir.
\end{abstract}

\section{Introducción}

En las últimas décadas, en el contexto pos dictatorial, la disputa por los derechos humanos quedó vigente en América Latina. No solo están presentes los activistas contra las violaciones de los derechos humanos atribuidas a las prácticas de las dictaduras militares o regímenes autoritarios. En el proceso de la transición a la democracia surgieron en América Latina nuevos movimientos sociales luchando por los derechos humanos en sus países (legal movements) y actores políticos que "tomaron la palabra" apoyándose en los derechos humanos "como forma de acción política". Frecuentemente se observa esta "toma de palabra", este empoderamiento por hablar, en el contexto de un referéndum constitucional o una consulta constitucional. Pero no necesariamente surgen legal movements en una disputa concreta por una reforma de la Carta Magna, sino por sus propias causas y motivos.

Podemos observar en América Latina que el señalamiento de las violaciones de los derechos humanos excedió cada vez más el límite de la violación de los derechos humanos políticos a priori, trayendo consigo los defectos de la democracia realmente existente, como por ejemplo los fraudes electorales, las desigualdades sociales, las discriminaciones raciales o las formas de impunidad.

1 Verónica, una mujer indígena, llora cuando habla de Manuela, fallecida el 22.12.1997 en Acteal, Chiapas (México) durante una matanza (Hernández Castillo 1998: 17). 
Al mismo tiempo el discurso de los derechos humanos involucra también a los hechos de ilicitud, que no están directamente inmersos en la relación entre el Estado y el individuo, sino más bien en espacios privados y entre particulares, como lo menciona Verónica en la cita anterior. La violencia doméstica contra las mujeres y los niños es, con seguridad, uno de los ejemplos más conocidos al respecto.

¿Pero qué significa la ampliación del discurso de los derechos humanos en un contexto jurídico cuyas características son definidas no tanto como defectuosas sino como corruptas? En la presente contribución tratamos de interpretar el hablar sobre los derechos humanos como una búsqueda social para expresar diferentes experiencias de injusticia en las protestas de diferentes grupos, tanto contra las circunstancias concretas, así como contra las formas en que se ejerce la injusticia. Lo que buscan los movimientos sociales al referirse a los derechos humanos es un lenguaje que les permite expresar la injusticia vivida en una forma jurídica. Para discutir la pregunta ¿qué es lo que convierte a los derechos humanos en un discurso legítimo sobre la experiencia de injusticia y hasta qué punto le condicionan barreras de sexo o de cultura?, nos orientamos en una contribución de Cornelia Vismann, ${ }^{2}$ que trata el texto de los derechos humanos como una "instancia elocutoria" (Instanz des Sprechens). Lo que nos interesa y tratamos de discutir con el apoyo del análisis de Vismann es si la autorización discursiva de las víctimas no solo hace hablar a los subalternos sino que los hace hablar más allá de una oposición "binaria" (Spivak 1994). La pregunta es si la referencia a un texto universal como los derechos humanos permite hablar sobre las experiencias de violencia vivida traspasando las fronteras territoriales, los contextos históricos, las diferencias étnicas y de género, y la polarización entre lo privado y lo público.

\section{Los derechos humanos como autorización de hablar}

En la búsqueda por el significado universal de los derechos humanos, los textos legales concretos de los diferentes estados no nos ayudan necesariamente - ya sea que faltan por completo, o porque están tem-

2 Cornelia Vismann (*26.05.1961 en Hankensbüttel; $† 28.08 .2010$ en Berlín) era profesora en derecho público, historiadora del derecho, filósofa y experta en teoría de comunicación. Este texto está basado en Vismann (1998). 
poralmente derogados o porque simplemente no se toman en consideración. Especialmente en regímenes autoritarios que no reconocen el Estado de Derecho y que no permiten una opinión pública crítica, falta el reconocimiento de los derechos humanos en la legislación. Pero tampoco los estados en transición de América Latina disponen de un instrumentario que pueda asegurar a sus ciudadanos sus derechos políticos y sociales, dentro y fuera del hogar. La gran mayoría de los Estados actuales -cualquiera que sean los atributos que caracterizan su democracia- son institucionalmente demasiado débiles para garantizar territorial y socialmente "la subsunción de lo privado bajo una burocracia disciplinadora de corte patriarcal y capitalista" (Benhabib 1992: 94) que permita la coexistencia de distintas formas de normas y valores. Valores sustentados por las iglesias y grupos religiosos, por las reglas y normas de diferentes sistemas sociales, entre otros, así como las distintas formas de hacer asuntos públicos o de imponer tabúes.

Pero como nos enseñan los textos de Vismann, los derechos humanos no existen solamente como instancia del derecho positivo, sino que se manifiestan en la voz de todos aquellos que denunciaron la injusticia. Así entendido, hay que reconstruir la disputa por los derechos humanos desde las iniciativas, acciones y movimientos sociales que toman la palabra de los derechos humanos para hablar sobre injusticias, desigualdades y violencias en diferentes contextos. En este sentido, Cornelia Vismann (1998: 283-304) ha calificado los derechos humanos como "instancia elocutoria". Tomando como ejemplo la Déclaration des droits de l'homme et du citoyen del año 1789, Vismann muestra el carácter ambiguo de los mismos: los derechos humanos fueron declarados como derechos y en consecuencia, formulados como textos legales, en los que la Asamblea Nacional, en este caso la francesa, concedió derechos a los ciudadanos franceses (aunque no todos fueron reconocidos como tales). Derechos humanos se considera a los derechos políticos ligados a ciertas condiciones y obligaciones de los ciudadanos, de los que en gran parte fueron excluidas las mujeres francesas y que no contenían ningún tipo de derecho. Pero al mismo tiempo, se trata de derechos que desde siempre fueron concedidos a todos los seres humanos y que son iguales en su aplicación e inalienables y que no están sometidos a ninguna condición ni dependen tampoco de las obligaciones del ciudadano. Son "derechos absolutos porque su existencia no está condicionada a ningún hecho que no sea el 
de la existencia del ser humano" (Denninger 1994: 80). Como se constata en el preámbulo de la Declaración, ${ }^{3}$ estos derechos absolutos forman un texto que fue escrito para evitar "el olvido". Según Vismann, a través de duplicar un texto o con la ayuda de un "truco lingüístico", todos los puestos legislativos están ocupados doblemente:

Hay dos legisladores: La Asamblea Nacional y el hombre; se formulan dos tipos de derecho: el de los ciudadanos franceses y el de todos los hombres; asimismo hay dos campos de aplicación: la República y la humanidad. Desde el punto de vista temporal esta Declaración está en vigor tanto desde que fue promulgada así como desde tiempos inmemoriales. Mediante la operación lingüística de una duplicación de todos los componentes legislativos, la Declaración marca la diferencia entre ciudadano (francés) y el hombre, entre la versión universal y particular, entre la validez histórica y la eterna, abriendo así el espacio en el cual la Declaración Universal de los Derechos Humanos se desarrolla paralelamente a la francesa y se sigue escribiendo, en cierto modo, por sí misma. Con ello se convierte literalmente en autolegislación que permite la autorización propia de cualquier individuo, mediante la autoridad del lenguaje jurídico - el cual funciona o se le apropia de forma semejante a un texto sagrado (Vismann 1998: 238ss.).

Sacando el texto de los derechos humanos de los contextos específicos de su origen, varían sus formas, pudiendo apropiárselo cada uno y cada una, trasladándolo a contextos diferentes para así reclamar cambios culturales y sociales.

De esta forma un texto legal de la Asamblea Nacional francesa se convierte en un metatexto, universalmente apropiable. Si se ve ligado a la codificación de los derechos políticos, los trasciende simultáneamente cuando, en lugar del legislador, del ámbito de aplicación y del titular de los derechos se presupone la misma unidad ficticia: el hombre, que es justamente una instancia abstracta (Vismann 1998: 284).

3 El preámbulo de la constitución francesa de 1791 fue la Declaración de los Derechos del hombre y del ciudadano dice: "Los representantes del pueblo francés, constituidos en Asamblea Nacional, considerando que la ignorancia, el olvido o el menosprecio de los derechos del hombre son las únicas causas de las calamidades públicas y de la corrupción de los gobiernos, han resuelto exponer, en una declaración solemne, los derechos naturales, inalienables y sagrados del hombre, a fin de que esta declaración, constantemente presente para todos los miembros del cuerpo social, les recuerde sin cesar sus derechos y sus deberes; a fin de que los actos del poder legislativo y del poder ejecutivo, al poder cotejarse a cada instante con la finalidad de toda institución política, sean más respetados y para que las reclamaciones de los ciudadanos, en adelante fundadas en principios simples e indiscutibles, redunden siempre en beneficio del mantenimiento de la Constitución y de la felicidad de todos". 
Con estos rasgos, la declaración de los derechos humanos es una infracción declarada del poder legislativo nacional, lo que significa una pérdida de soberanía de cada uno de los Estados, en el sentido de que al hombre se le concede el derecho a hablar y a contradecir cuando padece una injusticia por parte del Estado. Sin embargo, la Declaración francesa no sólo representa la lengua de los oprimidos en este momento histórico y en este lugar concreto, sino que los derechos humanos por sí mismos constituyen un lenguaje para poder declarar también otras experiencias de injusticia, pasadas y futuras.

Como "instancia elocutoria", los derechos humanos se presentan abiertos hacia nuevas experiencias de injusticia y reciben una dinámica propia, desligada del texto legal concreto. Los derechos humanos, al tratar el sentimiento de injusticia y experiencias que contradicen la ley, permiten hablar sobre las experiencias con el derecho, que no es tal, en los casos en que no está codificado o no se respeta. Pero esto implica también reclamar derechos concretos de un legislador concreto, siempre y cuando esté constituido como tal.

\section{El poder hablar de experiencias diferentes en el lenguaje de un texto abstracto}

Cabe preguntarse si esto es también válido para formas de violencia en los ámbitos privados e íntimos cuando estos se encuentran fuera del derecho codificado, tal y como lo explican la campaña internacional de las Naciones Unidas en los noventas "Los derechos de la mujer son derechos humanos" y las numerosas iniciativas regionales y locales para constituir la violencia sexualizada contra las mujeres como problema social. ${ }^{4}$ Es posible que los derechos humanos formulen también experiencias de injusticia fuera de las condiciones clásicas de opresión, aún cuando esto suponga ir contra el mainstream del mismo discurso pro derechos humanos. Este mainstream llegó a sus límites en los casos donde no era posible hacer responsable a ningún Estado de su fuerza represiva. El pensamiento clásico sobre los derechos humanos atrapado en la dicotomía entre lo privado y lo público, partía de la existencia de una dictadura que tortura y recorta las libertades

41993 Declaración de Viena: Todos los derechos humanos son universales, indivisibles e interdependientes y están relacionados entre sí. 1994. Convención Interamericana para Prevenir, Sancionar y Erradicar la Violencia contra la mujer. 
individuales o, por lo menos, la del Estado como sujeto de las opresiones, pero no disponía de jurisdicción en el caso de violaciones en lo privado.

Aunque en las décadas pasadas se haya reducido la cifra de estas formas clásicas de violaciones de derechos humanos en América Latina, éstas no se pueden considerar como superadas puesto que se mezclan con abusos difusos del poder, practicados por fuerzas paraestatales o por la mafia, los narcotraficantes, que quedan impunes. Pero si los derechos humanos no quieren perder su papel como "instancia elocutoria", sobre todo cuando ellos mismos no pueden funcionar como instancia de derecho, tienen que permitir una articulación discursiva de las violaciones que esté a la altura de esta transformación.

Esto implica también el poder formular las experiencias de injusticia concretas cuestionando la subyacente imagen del hombre que por regla general corresponde al varón blanco y burgués. Numerosos movimientos sociales y actores de la sociedad civil vuelven a recurrir al texto de fondo de los derechos humanos, texto que fue escrito contra el olvido, para que se cumpliese, sirviéndose del lenguaje de los derechos humanos para hacer públicas sus experiencias de injusticia. Pero es un camino largo de haber vivido una violencia física, de poder sentir que algo injusto está pasando, hasta ser consciente de que se trata de injusticia y que se tiene el derecho de reaccionar. ${ }^{5}$ También Verónica, mujer indígena de Chiapas, se refiriere a los derechos humanos, casi como un texto sagrado, para expresar su sentimiento de injusticia. Es por la palabra "derecho", inexistente en su idioma materno tzotzil, que Verónica ha podido abandonar a su marido, con el que la casaron a la edad de 14 años y con el que tiene siete hijos, y explicar a sus padres la situación (Hernández Castillo 1998). Justamente porque el hombre al que hacen referencia los derechos humanos es abstracto, cada individuo, como en el caso citado de Verónica, puede situarse en el texto en el lugar de la palabra "hombre", es decir, cada uno y cada una puede apropiarse una y otra vez del texto y dejarle hablar.

Cabe recordar que ya en la reunión constituyente de la Asamblea Nacional francesa no solamente no era un acto discursivo aislado sino una referencia práctica. El acto empírico histórico está entrelazado con

5 Como lo analiza Ströbele Gregor desde la experiencia de mujeres indígenas en los Andes (Ströbele-Gregor 1998: 45-56). 
acciones de grupos diferentes en lugares diferentes. La autodefinición del hombre abstracto (que identifica Vismann en la Declaración) permitió a muchos subalternos el "tomar la palabra" como habla de derecho. La proclamación de los derechos humanos llevó consigo en Haití, en el año 1791, un levantamiento de la población de color contra las clases superiores blancas, que culminó, en el 1804, con la liberación de los esclavos, el fin de la dominación francesa y en la proclamación de un Estado independiente. A los reyes de las colonias el metatexto permitió recordar que también eran hombres, seres humanos, como sujeto de derecho. En el mismo año en que tuvo lugar la reclamación de los colonizados, el 7 de septiembre de 1791, también Olympe de Gouges pidió la palabra para pronunciar la "Declaración de los Derechos de la Mujer y de las Ciudadanas". Su forma de proceder fue mucho más allá de la Declaración de los Derechos Humanos de 1948, ya que de Gouges utilizó justamente el metatexto y colocó a la mujer en el lugar del hombre. El esquema discursivo de igualdad y diferencia que articulan los derechos humanos no puede fallar más gráficamente que en la contraposición de ambos textos y hace más comprensible el hecho de que los derechos humanos de la mujer tienen que asegurarse también en el ámbito privado, como el matrimonio. ${ }^{6}$ De esta manera de Gouge abrió el camino para analizar la división entre lo público y lo privado y para acusar las violaciones de los derechos fundamentales en el matrimonio. Como ella, otras mujeres utilizan en muchos conflictos el lenguaje político de los derechos humanos, aún cuando éstos encierren una imagen del hombre definida por el status del ciudadano masculino. "Pues al servirse de este lenguaje, estaban solicitando su propia identidad. Con la misma acción cambiaron la cultura en la que se inspiraban" (Braig 2001: 25-38; Fox-Genovese 1998: 201; Gerhard 1990: 49-72).

Así leídos, los derechos humanos establecen un documento de autorización de los subalternos para formular experiencias de injusticia muy diversas y se relacionan con multitud de expresiones culturales de la subversión (también en lo privado). Ayudan a imaginar una instancia, cuyo actuar se legitima sin las leyes en vigor o, si es necesario,

6 En el articulo III se dice: El principio de toda soberanía reside esencialmente en la Nación que no es más que la reunión de la Mujer y el Hombre: ningún cuerpo, ningún individuo, puede ejercer autoridad que no emane de ellos. 
contra ellas. En los años ochenta del siglo pasado un gran número de organizaciones de familiares en todo el mundo se tomaron el derecho de hacer público su dolor privado y acusar a regímenes autoritarios, como lo hicieron las madres argentinas de la Plaza de Mayo, las viudas guatemaltecas, las madres del sábado turcas. Desde los años noventa, con la transformación neoliberal de la economía y de la política social, los movimientos sociales reaccionaron ante la marginación con la denuncia de una injusticia social a consecuencia de la falta de derechos sociales y constatando el aumento de la desigualdad económica y social. En los últimos tiempos ocurren actos violentos en espacios privados y públicos por actores privados, paraestatales y estatales que afectan la vida cotidiana y que se discuten como violación de los derechos humanos. Por el entrelazamiento entre actores estatales y no estatales, por ejemplo, en el combate contra el crimen organizado, la impunidad y la militarización de la seguridad pública por el estado, se articulan nuevos movimientos que forman legal coalitions (O'Donnell 1999) para exigir los derechos humanos. En el contexto mexicano de hoy día son otra vez familiares que rompen el silencio en manifestaciones de silencio para pedir paz con justicia y dignidad. ${ }^{7}$

$\mathrm{Al}$ igual que el reconocimiento de la violencia física y sexualizada y de otras formas de violencia estructural como problema social y político, resta la tarea de formular al mismo tiempo los derechos humanos como derechos codificados, y de reclamarlos en un Estado concreto que sea capaz de imponer sanciones.

La Declaración General de los Derechos Humanos posee así la función de un imperativo a expresarse - a la expresión de cada una de las declaraciones particulares de los derechos humanos, que se quedan sin nombrar en la versión general. La misma se irá completando hasta que todas las declaraciones particulares de los derechos humanos tengan lugar bajo el techo de las generales (Vismann 1998: 292 y ss).

7 Después de la muerte de su hijo, el poeta Javier Sicilia organiza una gran manifestación que sale el 5 de mayo 2011 de Cuernavaca, Morelos, para llegar el 8 de mayo al Zócalo de la Ciudad de México. Esta manifestación lleva por nombre "La marcha nacional por la paz con justicia y dignidad". Al finalizar la marcha en el Zócalo, Sicilia demandó al presidente de la república retirar el Secretario de Seguridad Pública, además de solicitar el "combatir corrupción, impunidad y ganancias del crimen". 


\section{Tomar la palabra como acción política}

Sin reforzar el lado político práctico de los derechos y la vinculación de lo discursivo, la "instancia elocutoria", con lo practico, "instancia del derecho" codificado, persiste el riesgo de que el metatexto de los derechos humanos se pierda en un cotorreo polifónico y en una cacofonía. Un vínculo podría formar la reforma de la propia constitución. Desde décadas las cartas magnas de los países de América Latina se encuentra en disputa y muchas de ellas han tenido cambios profundos. Fue por los movimientos sociales, especialmente por los legal movements de organizaciones indígenas, que en los noventas se realizaron reformas constitucionales significantes, especialmente en Colombia (1990-1991), Perú (1993), Ecuador (1998) y Bolivia (1994-1995, 2009). México fue el primer país del Subcontinente en ratificar el Convenio 169 sobre los Pueblos Indígenas de la Organización Internacional del Trabajo (OIT), pero no participó en este proceso de las reformas constitucionales que encontró su punto de referencia jurídico en el Convenio 169. En comparación con los otros países, la constitución mexicana ha sido objeto de pocas modificaciones (HernándezDíaz 2010: 141 y ss).

Es sobretodo el movimiento zapatista que tomó desde los noventas la palabra como forma de acción refiriéndose a la Carta Magna de la nación mexicana. Ningún otro movimiento social, ninguna otra guerrilla en Latinoamérica ha luchado tan fuertemente con las palabras y tan poco con las armas. Su estrategia de comunicación ${ }^{8}$ trató desde su comienzo de no conducir el discurso público como un monólogo y su finalidad no fue sólo la resonancia internacional, la cual durante algún tiempo fue ciertamente muy exitosa. La comunicación zapatista a través de comunicados tenía como finalidad desde su comienzo apuntar a la constitución nacional y al parlamento como núcleos centrales de la democracia posible, y no al sistema presidencial.

Con el pronunciamiento, mundialmente famoso y de alta empatía, "Ya basta", comienza el 1 de enero de 1994 una rebelión de las pala-

8 "El discurso no es simplemente aquello que traduce las luchas o los sistemas de dominación sino aquello por lo que y por medio de lo cual se lucha”, escribió en 1980 citando a Foucault (Die Ordnung der Diskurse, 1994) un estudiante de la UNAM en la ciudad de México, Vicente Guillén. Sobre el discurso como lucha: (Huffschmid 2004). 
bras, de los "indios", de las mujeres y niños al margen del mundo. Ellos se toman el derecho a hablar, a contradecir, y tomando la palabra, legitiman su existencia hasta ahora desconocida. Ironía y desmesura se expresan por años en escenificaciones múltiples de la propia existencia, de la cual la opinión pública nada sabía y tampoco quería saber y sigue sin querer saber (Huffschmid 2004).

Si uno solamente se fija en el silencio actual de esta forma de comunicación ejercido por varios años a niveles múltiples, y ciertamente original, se queda uno con el amargo resultado de que no fue mucho más que un monólogo creativo en el contexto de la tercera ola de la democratización. ${ }^{9}$

Cabe añadir que el "tomar la palabra" del movimiento Zapatista no solamente crea una opinión pública crítica, dentro de la cual los subalternos tienen un espacio de expresión, ya que estos al hablar, se manifiestan al mismo tiempo como ciudadanos que quieren participar en los procesos de decisión legislativos a través del articularse como protagonistas de la soberanía popular. Ya desde su primer comunicado se refieren a la constitución del país para legitimar su hablar:

Para evitarlo y como nuestra última esperanza, después de haber intentado todo por poner en práctica la legalidad basada en nuestra Carta Magna, recurrimos a ella, nuestra Constitución, para aplicar el Artículo 39 Constitucional que a la letra dice: 'La soberanía nacional reside esencial y originariamente en el pueblo. Todo el poder público dimana del pueblo y se instituye para beneficio de éste. El pueblo tiene, en todo tiempo, el inalienable derecho de alterar o modificar la forma de su gobierno.'

Después de sus primeros acciones en 1994 el movimiento neozapatista obligó al Estado mexicano de crear espacios de dialogo, espacios para poder hablar y ser escuchados, como la Comisión de Paz y Concordia para la Pacificación en Chiapas (COOPA). Era un órgano plural del poder legislativo con la tarea de mediación entre el poder ejecutivo y la guerrilla. Un resultado de esta negociación era, que se consideró en los Acuerdos de San Andrés, la necesidad de reformar algunos artículos de la Constitución (Hernández Díaz 2020: 143). En 2001 en el contexto de la Marcha Zapatista lograron indígenas (mujeres y hom-

9 Entre otros véase Huntington (1991). Para una versión critica de la comunicación véase (Maus 2007: 350-382). Maus se pregunta si, en el contexto de la democracia global, la cual se determina frecuentemente por un criterio único (que seria la existencia de una opinión critica mundial), no existe el peligro de reducir esta democracia a la mitad de su valor, convirtiéndola solo en comunicación. 
bres) hablar desde una posición subalterna frente al parlamento en sus idiomas propios para reclamar reformas constitucionales. En todo este tiempo logró el movimiento guerrillero no solo defenderse desde el inicio contra la represión, sino que sigue rechazando las ofertas clientelistas.

El verdadero mérito de los zapatistas radicó en dos cosas: en su capacidad para enlazar las demandas de democracia, justicia y libertad que ellos enarbolaban con la demanda indígena de autonomía, y en la tribuna nacional que construyeron para el debate de este tema, con lo que lograron que la reivindicación de los pueblos indos alcanzan una resonancia inusual. El vínculo resultó enormemente fecundo, y eficaz la apertura del espacio público (Díaz Polanco 1997: 171)

Aún no lograron la gran reforma de la Carta Magna como las organizaciones indígenas lo esperaban, encontraron puentes entre la "instancia elocutoria" y la "instancia del derecho". Así en la reforma constitucional de 2001 las organizaciones dejaron huellas notables, que hoy en día sirven como base para discutir la autonomía municipal y otras demandas de los movimientos indígenas.

\section{Bibliografía}

Benhabib, Seyla (1992): "Models of Public Space: Hannah Arendt, the Liberal Tradition, and Jürgen Habermas". En: Calhoun, Craig J.: Habermas and the Public Sphere. Cambridge: MIT-Press, pp. 73-98.

Braig, Marianne (2001): "Repensando los procesos de violencia en América Latina. La violencia sexualizada como violación de los derechos humanos". En: Bodemer, Klaus/Kurtenbach, Sabine/Meschkat, Klaus (eds.): Violencia y regulación de conflicto en América Latina. Caracas: Nueva Sociedad, pp. 25-38.

Braig, Marianne/Anne, Huffschmid (eds.) (2009): Los poderes de lo público. Madrid: Iberoamericana/Frankfurt am Main: Vervuert.

Denninger, Erhard (1994): Menschenrechte und Grundgesetz. Weinheim: Beltz Athenäum.

Díaz Polanco, Héctor (1997): La rebelión zapatista y la autonomía. México, D.F., Siglo XXI.

Fox-Genovese, Elisabeth (1998): "Freiheitskämpfe: Frauen, Sklaverei und Gleichheit in den Vereinigten Staaten". En: Hufton, Olwen H. (ed.): Menschenrechte in der Geschichte. Frankfurt am Main: Fischer Taschenbuch-Verlag, pp. 194-235.

Gerhard, Ute (1990): Gleichheit ohne Angleichung. Frauen im Recht. München: C.H. Beck. 
Hernández-Díaz, Jorge (2010): “La construcción de ciudadanías postliberales. Los reclamos de autonomía municipal y demandas indígenas en México". En: Latin American Research Review 45,4, pp. 138-165.

Hernández Castillo, Rosalva Aída (1998): La otra palabra. Mujeres y violencia en Chiapas antes y después de Acteal. México, D.F.: CIESAS.

Huffschmid, Anne (2004): Diskursguerilla: Wortergreifung und Widersinn. Die Zapatistas im Spiegel der mexikanischen und internationalen Öffentlichkeit. Heidelberg: Synchron Wissenschaftsverlag.

Huntington, Samuel (1991): The Third Wave. Democratization in the Late Twentieth Century. Norman: University of Oklahoma Press.

Maus, Ingeborg (2007): "Verfassung oder Vertrag. Zur Verrechtlichung globaler Politik". En: Niesen, Peter/Herborth, Benjamin (eds.): Anarchie der kommunikativen Freiheit. Jürgen Habermas und die Theorie der internationalen Politik. Frankfurt am Main: Suhrkamp, pp. 350-382.

O'Donnell, Guillermo (1999): "Horizontal Accountabilty in New Democracies". En: Schedler, Andreas/Diamond, Larry J./Plattner, Marc F. (eds.): The Self-restraining State. Power and Accountability in New Democracies. Boulder/London: Lynne Rienner Publishers, pp. 29-51.

Spivak, Guyatri (1994): "Can the Subaltern Speak". En: Willimas, Patrick/Chrisman, Laura: Colonial Discourse and Postcolonial Theory. New York: Colombia Press, pp. 66-111.

Ströbele-Gregor, Juliana (1998): "Gewalterfahrung von Frauen in den Anden. Unrechtsempfinden, Unrechtsbewusstsein, Rechtsdenken und Wandlungsprozesse in indianischen Dorfgemeinschaften". En: Braig, Marianne/Gerhard, Ute (eds): Frauenrechte sind Menschenrechte. Frankfurt am Main: J. W. Goethe-Universität, pp. 45-56.

Vismann, Cornelia (1998): "Menschenrechte: Instanz des Sprechens - Instrument der Politik". En: Brunkhorst, Hauke (ed.): Demokratischer Experimentalismus. Politik in der komplexen Gesellschaft. Frankfurt am Main: Suhrkamp, pp. 283-304. 